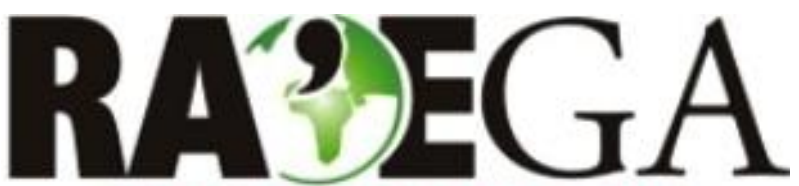

O ESPAÇO GEOGRÁFICO EM ANÁLISE

\title{
A CENTRALIDADE INTRAURBANA A PARTIR DA ANÁLISE DE FRANQUIAS E FILIAIS EM CIDADES MÉDIAS
}

\section{THE INTRA-URBAN CENTRALITY FROM THE ANALYSIS OF FRANCHISES AND SUBSIDIARIES IN INTERMEDIATED CITIES}

\author{
Heloísa Mariz Ferreira ${ }^{1}$
}

\section{RESUMO}

No presente artigo, nosso objetivo consiste em tecer análise comparativa e relacional entre as áreas centrais de cidades médias policêntricas, em especial Presidente Prudente, situada no Oeste do estado de São Paulo, por meio da inferência da complexidade do capital das empresas identificada, de modo quantitativo e qualitativo, pela presença de franquias e filiais. Esta escolha se justifica pela expressiva preferência de consumidores por estes estabelecimentos, cujas dinâmicas são representativas de vínculos e interações espaciais com o capital externo e lógicas espaciais subjacentes, pertencentes a processos de desconcentração espacial de atividades do centro principal para novas áreas centrais e segmentação socioespacial dos espaços de consumo. De modo geral, as lógicas espaciais atinentes privilegiam áreas que correspondem a signos de modernidade, como shopping centers, e são parte do processo de reestruturação espacial, que implica em alteração do conteúdo e da relação entre centro e periferia. Entretanto, a despeito da magnitude de tais dinâmicas e processos, o centro mantem-se importante mesmo nesse quadro de policentrismo, considerando a seletividade funcional dos processos de desconcentração espacial, movimentos contrários a estes e o caráter múltiplo das práticas espaciais de consumo. Isto demanda a análise relativização das repercussões da conformação de estruturas urbanas policêntricas e da perda de importância do centro.

Palavras-chave: Cidades Médias; Policentralidade; Franquias; Filiais; Presidente Prudente-SP.

\section{ABSTRACT}

In this article, our objective is to provide a comparative and relational analysis of polycentric, intermediated city centers, particularly that of Presidente Prudente, located in the west of São Paulo state. This analysis will be conducted by inferring the complexity of enterprise capital, identified quantitatively and qualitatively by the presence of franchises and subsidiaries. This choice is justified by customers' preference for these establishments, whose dynamics represent spatial links and interactions with external capital and underlying spatial logic. Spatial deconcentration from the main center to new areas is part of the socio-spatial segmentation of consumer areas. Generally, spatial logic favors areas that correspond to signs of modernity, such as shopping malls, and are part of spatial restructuring, which alters the content and the relationship between the center and the periphery. Despite the magnitude of such dynamics and processes, the center remains important within this framework of polycentrism when considering the functional selectivity of spatial deconcentration, the movements against them, and the multiple characters of space consumption practices. This restructuring requires an analysis of the relative repercussions of polycentric urban structure conformation and the loss of centers importance.

Key-words: Medium-Sized Cities; Poly-Centrality; Franchises; Subsidiaries; Presidente Prudente, SP.

Recebido em: 21/03/2017

Aceito em: 02/08/2018

\footnotetext{
1 O artigo é resultante da pesquisa "O centro consolidado e o centro principal nas cidades policêntricas: transformações e permanências em Marília, Presidente Prudente e São Carlos-SP", tese finalizada e financiada pela Fundação de Amparo à Pesquisa do Estado de São Paulo (FAPESP), processo 2016/03757-3.

1 Universidade Estadual Paulista Júlio de Mesquita Filho, Campus de Presidente Prudente, e-mail: heloisamariz@gmail.com
} 
Ferreira, H. M.

\section{A CENTRALIDADE INTRAURBANA A PARTIR DA ANÁLISE DE FRANQUIAS E FILIAIS EM CIDADES MÉDIAS}

\section{INTRODUÇÃO}

Para compreensão de espaços de consumo em cidades policêntricas, é de fundamental importância a referência entre as áreas centrais e sua articulação a um conjunto, já que lógicas espaciais de empresas e práticas espaciais de consumo de citadinos envolvem escolhas pelas áreas centrais. Valendo-nos de uma perspectiva comparativa e relacional, proposta por Whitacker (2015), damos foco em nossa pesquisa às firmas que se organizam como franquias e filiais.

Esta opção se justifica pela identificação $^{2}$ da expressiva atração de consumidores exercida por tais unidades, que reforçam a centralidade das áreas centrais em que se situam e apresentam lógicas espaciais que são reveladoras e condicionantes das diferenças $^{3}$ entre as áreas em estruturas policêntricas.

Para Sposito (2013), a policentralidade consiste em estrutura urbana marcada pela implantação de grandes superfícies comerciais e de serviços que implicam em mudanças significativas em cidades até então marcadas pela primazia do centro, sendo este único ou coexistente a outras áreas centrais de importância secundária. De modo distinto a estas, as novas áreas desempenham relações não apenas de complementaridade, mas estabelecem concorrência com o centro, como também apontou Whitacker (2015).

Isto porque, segundo Sposito (2013), estes novos espaços atraem frequentadores do conjunto da cidade e da região, numa posição hierárquica semelhante ou concorrente à do Centro, provocando redefinição das práticas espaciais de consumo, dinâmicas estas condicionadas pela difusão do transporte

\footnotetext{
${ }^{2}$ Identificamos que as firmas que se organizam como franquias e filiais consistem nas lojas mais visitadas por frequentadores do centro, quando da análise de enquetes realizadas nesta área central pela equipe do Projeto Temático "Lógicas econômicas e práticas espaciais contemporâneas: cidades médias e consumo", do qual também fazemos parte.
}

individual e aporte de infraestruturas em áreas geometricamente e/ou socialmente periféricas, transformadas nas últimas quatro décadas, o que requer a consideração de suas pluralidades, como frisou Sposito (2007).

Ainda que estas dinâmicas repercutam de vários modos no centro, com redefinições do seu conteúdo, a partir do predomínio do consumo por citadinos de média a baixa renda e de empresas que buscam atendê-los, e de suas funções, com o deslocamento de estabelecimentos relativos ao comércio de vestuários e calçados (MATTOS, 2016), por exemplo, esta área central mantém importância significativa, derivada da seletividade do processo de desconcentração espacial de atividades e concentração de outras, o que será demonstrado com a análise da localização de unidades franqueadas e filiais e a comparação da presença destas unidades conforme os ramos de atividade.

Isto posto, não obstante as relações de concorrência tecidas pelas novas áreas centrais, o centro é espaço importante às escolhas empresariais, constituindo condição aos novos processos enquanto rugosidade (SANTOS, 1996), o que exige seu destaque na análise.

Esta análise deve levar em contar que as ações que comandam tais processos e dinâmicas estão articuladas a escalas mais amplas, como manifestação dos processos de concentração e centralização econômicas dos grandes grupos empresariais, que expandem suas atuações, compondo mudanças nos papéis e incremento das funções das cidades médias na rede urbana, como será detalhado nos tópicos seguintes.

Diversos trabalhos propiciaram contribuições teórico-metodológicas relevantes

3 Entre as outras diferenças, associadas às franquias e filiais, destacamos concentrações absolutas e relativas de atividades comerciais e de serviços; especialização funcional; densidade de inovações tecnológicas (WHITACKER, 2007); modos de apropriação e valorações simbólicas; tempos acumulados e status do uso residencial, dentre outros elementos ou processos. 
Ferreira, H. M.

\section{A CENTRALIDADE INTRAURBANA A PARTIR DA ANÁLISE DE FRANQUIAS E FILIAIS EM CIDADES MÉDIAS}

acerca destas ações e dos novos papéis, como os de: Catelan (2014), acerca das interações espaciais não-hierárquicas; Castro e Engel (2015), sobre a redefinição impulsionada por shopping centers da centralidade interurbana; Sodré e Pereira (2015), que tratou das interações interescalares na rede urbana; e Sposito (2006, 2007), que abordou reestruturações espaciais na escala da rede urbana e das cidades. Com enfoque distinto, nosso objetivo consiste, embora articulado ao âmbito da rede urbana, em compreender estas mudanças no espaço das cidades, posto que os novos empreendimentos priorizam de modo geral a localização periférica, com mudanças em estruturas até então marcadas por centro único ou em posição hierárquica superior a áreas centrais secundárias.

Este esforço analítico se dá a partir de Presidente Prudente, com 223.749 habitantes, de acordo com estimativa populacional do Instituto Brasileiro de Geografia e Estatística (IBGE, 2016).

Como identificaram Sposito (2001) e Whitacker (1991, 1997), sua estrutura é marcada pelo surgimento de novas áreas centrais, a partir dos anos de 1980, com instalação de shopping centers e hipermercados (Sposito, 2001), que se somaram a subcentros e eixos de desdobramentos já existentes (Whitacker, 1991, 1997; Sposito, 2001), que, em diferentes proporções, implicaram em mudanças no centro. O processo se assemelha ao ocorrido em cidades de mesma tipologia urbana, como apreendido nos trabalhos de Cleps (2004), Oliveira Júnior (2008), Sposito (2007, 2013) e Whitacker (2003, 2015).

A partir do exposto, a análise proposta permite depreendermos a densidade de vínculos e interações espaciais com o capital externo, que compõem diferenças observadas entre áreas centrais em cidades policêntricas e estão atreladas a processos de desconcentração espacial de atividades, distinção/especialização funcional e segmentação socioespacial.
Para a análise das áreas centrais, por meio da comparação quantitativa e qualitativa da complexidade do capital das empresas, selecionamos como procedimento principal a identificação de franquias e filiais, em trabalhos de campo nos espaços de consumo e checagem em sites de shopping centers, tarefa antecedida pela tabulação de empresas franqueadas e filiais e a origem dos respectivos capitais.

Feito isto, voltamo-nos ao detalhamento de informações sobre as atividades desenvolvidas pelas empresas, suas escalas de atuação e as áreas centrais escolhidas, para compreendermos suas lógicas espaciais. No caso das franquias, também coletamos informações de preços de aquisição no sítio eletrônico da Associação Brasileira de Franchising (ABF) e das empresas franqueadoras, para apreensão do porte do capital de quem as adquire.

Para organização das informações, elaboramos quadros acerca de ramos com maiores números absolutos de franquias e filiais, que propiciaram apreensão de panorama geral da complexidade do capital das áreas centrais e das lógicas espaciais de empresas que se mostram díspares com relação a escolhas locacionais, possibilitando, com isso, compreensão de dinâmicas contrárias, de perda de importância e reafirmação da centralidade do centro.

Com isso, foi possível realizarmos a análise quantitativa (concentração absoluta) e qualitativa (atividades econômicas, processos e lógicas espaciais subsumidas) entre as áreas centrais, tendo como pressuposto a importância do centro, a despeito das mudanças de peso advindas, enquanto condicionamento aos novos processos, especialmente ao policentrismo e à reestruturação das cidades. Assim, o centro é ainda privilegiado nas escolhas de localização de empresas de capital externo e constitui-se, ainda que ponderando-se a ocorrência do policentrismo, como o centro principal de Presidente Prudente.

\section{MATERIAIS E MÉTODOS}


Ferreira, H. M.

\section{A CENTRALIDADE INTRAURBANA A PARTIR DA ANÁLISE DE FRANQUIAS E FILIAIS EM CIDADES MÉDIAS}

\section{RESULTADOS E DISCUSSÃO}

\subsection{Processos multiescalares e expansão do capital \\ A expansão das atividades do setor} terciário, a partir da criação de filiais e adoção de franqueamento, está atrelada a mudanças da acumulação do capital que demandam ajustes teóricos na compreensão das escalas (MELAZZO, CASTRO, 2008; SILVEIRA, 2004). São transformações em curso, não restritas à produção, segundo Harvey (1992), posto que abrangem aceleração da inovação tecnológica e de produtos, possíveis graças à importância adquirida pelo consumo, condição às modificações na produção. São mudanças profundas que permitem a convivência entre crises e aumento da lucratividade.

Isto se dá graças ao meio conceituado por Santos (1996) como técnico-científicoinformacional, que autoriza um comando unificado ao capital e a formação de uma maisvalia mundial através da informação, fundamental às empresas na busca por maior escala de atuação, em dinâmicas de desconcentração espacial com unidades articuladas num mercado global.

Com isso, concordamos com Brenner (2009), quando este aponta que as escalas são socialmente produzidas, multidimensionais, historicamente transformadas e fortemente interconectadas. As relações interescalares têm sido intensificadas desde a década de 1980, período de mudanças profundas ligadas à relativização de hierarquias espaciais até então consolidadas.

As novas escalas de acumulação implicaram em novos papéis e funções às cidades médias na rede urbana (SPOSITO, 2007), concomitantes a redefinições da centralidade intraurbana, devido às recentes dinâmicas de intensificação da centralização e desconcentração espacial do capital.

A centralização diz respeito, segundo Lencioni (2008), ao controle dos capitais e ciclos de valorização, através da gestão da empresa e do desenvolvimento da informação, no comando de unidades distantes do ponto de vista territorial (LENCIONI, 2008), como são as franquias e filiais. O processo de centralização do capital implica, então, na não coincidência territorial entre a ação e o resultado, o que explica Santos (1996), com distintas escalas de atuação entre as empresas.

Ao tratar de áreas metropolitanas e dos serviços avançados, Lencioni (2008) aponta a conformação de hierarquias, a partir dos vínculos internacionais das atividades desenvolvidas. A despeito das diferentes tipologias urbanas e natureza das atividades analisadas por Lencioni (2008), cremos ser profícua a consideração destas dinâmicas na análise da centralidade intraurbana, posto que, concomitante à centralização do capital, Lozano e Sposito (2015) destacam desconcentração espacial de sucursais que, embora exiba privilégio em grandes cidades e áreas metropolitanas, também são instaladas em cidades médias, concomitante à proliferação de franquias, identificadas por Ortigoza (1996). As áreas centrais (dimensão intraurbana) apresentam, então, diferentes ligações e interações espaciais com as metrópoles e o exterior (na dimensão interurbana), em função da acentuação da competitividade entre empresas, centralização do capital e ampliação dos mercados consumidores.

Franquias e filiais consistem em modos de organização da comercialização de bens e serviços que apresentam, contudo, importantes distinções. O primeiro modo constitui, conforme Silva e Azevedo (2007, p. 130), em acordo organizacional entre franqueado e franqueador, o proprietário da marca e do modelo de gerenciamento, que os fornece àquele, em troca do pagamento de taxa de franquia, junto a outros encargos e participação no lucro do estabelecimento. Os dados que coletamos, abordados adiante, evidenciam expressiva opção por franquias por empresas do ramo do comércio de vestuário e calçados. Suas lógicas espaciais são indicativas de escolhas por espaços de consumo segmentados, ligadas 


\section{A CENTRALIDADE INTRAURBANA A PARTIR DA ANÁLISE DE FRANQUIAS E FILIAIS EM CIDADES MÉDIAS}

especialmente à desconcentração espacial de atividades e surgimento de novas áreas centrais.

Já no que concerne às filiais, são lojas de propriedade de um mesmo grupo empresarial, subordinadas à integração vertical. Nesta integração, a sede comanda redes de filiais, de sua propriedade (SILVA, AZEVEDO, 2007), num compartilhamento, segundo Salgueiro (1996), de políticas de vendas e marketing, dependentes de comando central. Em nossa pesquisa identificamos por exemplo que, sendo mais atreladas ao reforço e manutenção da centralidade do centro principal, empresas de comercialização de eletroeletrônicos com atuação em Presidente Prudente privilegiam este modo de organização e exibem tendência a localizar-se junto àquela área que, de modo ímpar, atrai consumidores de grande diversidade de segmentos socioeconômicos.

Além do grande capital externo, conferimos atenção à organização dos capitais locais em franquias e filiais, que podemos supor que sejam favorecidos, baseando-nos em Silveira (2014, p. 163), pela banalização da técnica que permite ao circuito inferior da economia tecnologia e organização formuladas no circuito superior, embora isto não implique na permanência destas empresas neste circuito, em função da constante incorporação de capitais e organização continuamente requeridas.

Assim, os processos de desconcentração espacial de grandes grupos empresariais repercutem, com distintas escalas de atuação, não somente na divisão territorial do trabalho no âmbito da rede urbana mas, de modo articulado, na centralidade intraurbana, com lógicas espaciais de grupos empresariais que são distintas de acordo com as atividades desempenhadas e os processos gerados, em novos meios de organização e formas de comercialização (ORTIGOZA, 1996; ORTIGOZA, 2003) como parte da globalização econômica tratada por Corrêa (1999).

São processos presentes na produção do espaço de cidades médias, em especial nas últimas três décadas, como os relativos à emergência de novas áreas centrais, diferentes entre si, com relações de complementaridade e concorrência (SPOSITO, 2013; WHITACKER, 2015), e segmentação socioespacial destes espaços. Contudo, a chegada do novo não implica em estruturas inéditas ou completamente refeitas, mas se combina ao preexistente, que, em diferentes intensidades, permanece (SANTOS, 1994).

Assim, apesar dos efeitos destes novos processos na centralidade, a serem abordaremos no tópico seguinte, há lógicas associadas a permanência de unidades no centro principal e a novas instalações, em movimentos contrários, de reforço da centralidade desta área, uma condição preexistente.

\section{2. $\mathrm{O}$ centro e as novas áreas centrais}

As reestruturações promovidas pelo capital reverberaram sobre as cidades capitalistas que, conforme Soja (1993), exibiram, nas últimas décadas, reestruturações espaciais, como efeito da espacialização do capital. Como parte deste processo, no âmbito da rede urbana, teve início uma reestruturação urbana que, conforme Sposito (2007), consiste em ampliação da divisão territorial do trabalho, o que acarretou, para o caso das cidades médias, reforço de suas relações, entre cidades do mesmo porte e as cidades de papéis mais amplos.

O processo de reestruturação se manifesta também na dimensão intraurbana e, com isso, de acordo com Sposito (2007), observa-se alterações das lógicas de estruturação, mais complexas, a partir de decisões e ações externas aos poderes político e econômico locais, ainda que a eles associados.

Em cidades médias, estes processos tiveram início nas últimas décadas do século $X X$, com a instalação de shopping centers e hipermercados, que observamos na análise de Presidente Prudente, de complexa estrutura espacial, em razão dos novos conteúdos do centro e do que se pode compreender como 
Ferreira, H. M.

\section{A CENTRALIDADE INTRAURBANA A PARTIR DA ANÁLISE DE FRANQUIAS E FILIAIS EM CIDADES MÉDIAS}

periferia e da emergência de novas áreas centrais, que se somam aos subcentros ${ }^{4}$ e eixos de desdobramentos ${ }^{5}$, representados na Figura 1.

Segundo Sposito (2013), as grandes superfícies são rapidamente implantadas, capazes de redefinir lógicas de estruturação do espaço intraurbano e impactar o centro principal, pois além disso estão direcionados, em princípio, a públicos de poder aquisitivo mais elevado. Mais do que muitas, são diferentes áreas centrais, o que caracteriza, para a autora, a policentralidade. Em complemento ao debatido por Sposito (2013), agregamos à noção de policentralidade, neste caso específico, não apenas as grandes superfícies de consumo tal qual apresentado por essa autora em identificação direta aos shopping centers e hipermercados, mas também a outras áreas tais como subcentros e eixos de desdobramento, como trabalhado por Whitacker (2015).

Entre as mudanças da centralidade intraurbana, destacamos o processo de desconcentração espacial de atividades terciárias do centro principal, já identificado por Whitacker (1997). No caso da cidade em estudo, a saída foi direcionada a áreas mais recentemente erigidas, como eixos de desdobramento, mas, sobretudo, aos espaços de consumo modernos, os dois shopping centers, Prudenshopping e Parque Shopping Prudente. Enquanto áreas centrais implantadas por ações de segmentação da clientela, atraem instalação de franquias e filiais vinculadas, principalmente, ao capital externo.

\footnotetext{
${ }^{4}$ De modo geral, para Corrêa (1989), Sposito (1991) e Villaça (2001), subcentros são áreas centrais com grande diversidade de atividades, semelhante ao centro, porém com menor aglomeração de estabelecimentos e atração de consumidores, o que conferimos em análise de Presidente Prudente, em coleta de dados de usos do solo no Cadastro Nacional de Endereços para Fins Estatísticos (CNEFE), produzido pelo Instituto Brasileiro de Geografia e Estatística (IBGE), organização dos dados em classes de atividades conforme a Classificação Nacional de Atividades (CNAE), disponibilizada pelo IBGE, e análise de entrevistas com citadinos realizadas por pesquisadores do Projeto Temático de que fizemos parte. Os três subcentros identificados, também apreendidos por Pereira (2002),
}

exibem diversidade considerável de atividades e distinções quanto ao porte da concentração de estabelecimentos e atração de consumidores, com poucos impactos na estruturação, se comparado aos shopping centers e hipermercados.

5 Segundo Sposito (1991) e Whitacker (1991, 1997), tais espaços consistem em desdobramento do centro, acompanhado de especialização funcional e/ou socioeconômica, que identificamos por meios dos procedimentos aludidos na nota 4, contíguos ou não ao centro. Dos eixos representados na Figura, os eixos 1, 2, 3 e 4 exibem especialização, ao passo que os demais não apresentam. Não implicam policentralidade, em distinção a shopping centers e hipermercados. 
Ferreira, H. M.

\section{A CENTRALIDADE INTRAURBANA A PARTIR DA ANÁLISE DE FRANQUIAS E FILIAIS EM CIDADES MÉDIAS}

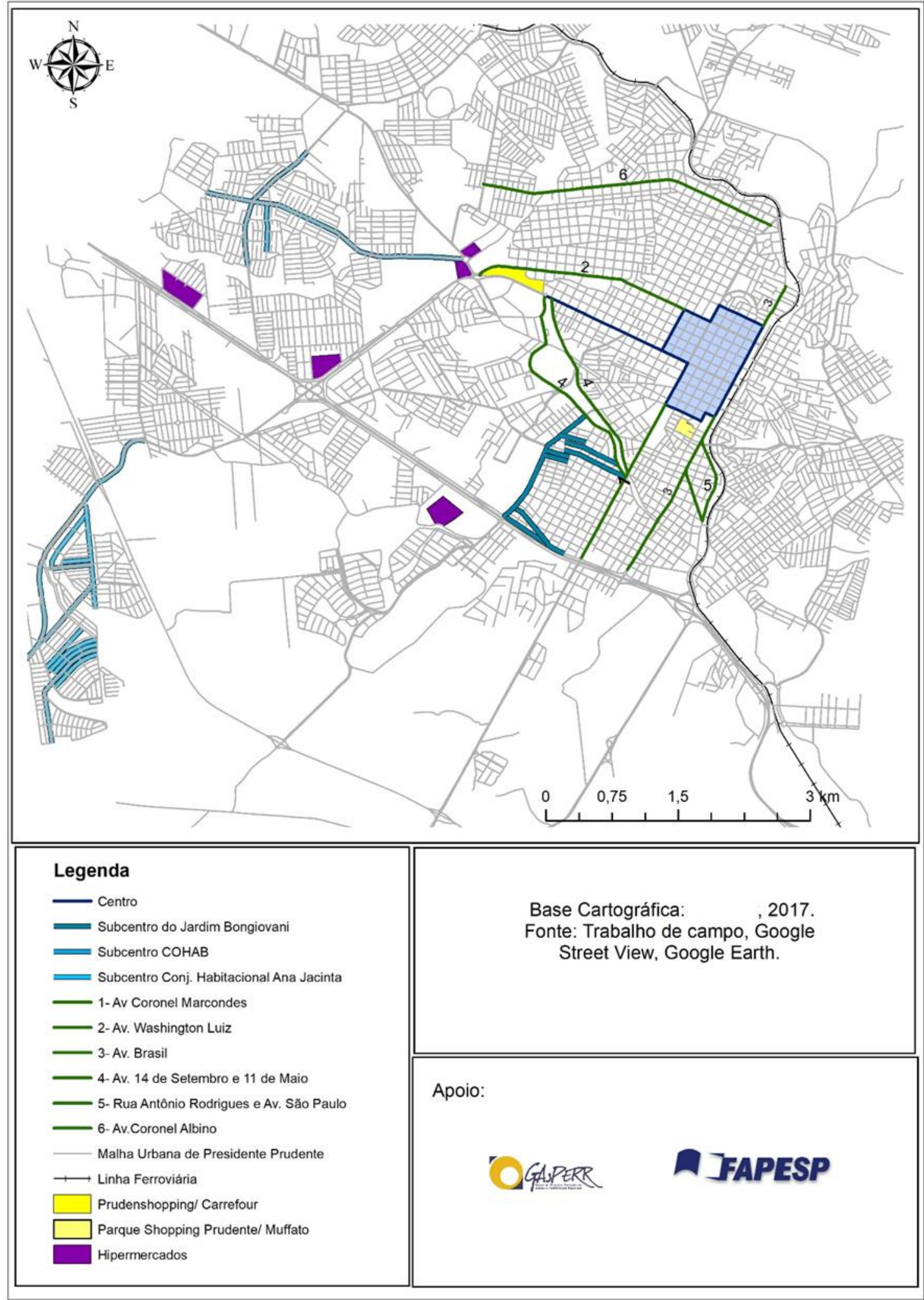

Figura 1 - Áreas centrais de Presidente Prudente, 2018. 
Ferreira, H. M.

\section{A CENTRALIDADE INTRAURBANA A PARTIR DA ANÁLISE DE FRANQUIAS E FILIAIS EM CIDADES MÉDIAS}

$\mathrm{Na}$ figura 1, com base no círculo cromático, representamos áreas de considerável concentração de atividades terciárias. O centro, em azul escuro; subcentros, representados em tonalidade mais clara àquele, sendo o do Jardim Bongiovani de maior importância6; e o do bairro Ana Jacinta, de inferior relevância; eixos de comércio e serviços, não necessariamente subordinados ao centro; e shopping centers e hipermercados, em roxo e amarelo, respectivamente, que promovem, em alguns casos, relações de concorrência e complementaridade ao centro.

Embora a estrutura espacial de Presidente Prudente seja marcada pela presença de dois shopping centers, as mudanças subsumidas são distintas, visto que o Prudenshopping constitui grande espaço voltado majoritariamente a segmentos socioeconômicos ligeiramente mais altos e número expressivo de franquias e filiais, em coexistência ao Parque Shopping Prudente, espaço de menores dimensões, com público alvo mais amplo, inclusive camadas de média a média-baixa renda, e quantidade inferior de lojas.

Isto constitui o primeiro ponto a destacar, que corresponde à necessária relativização da força das dinâmicas de constituição da policentralidade, advindas da conformação de novas áreas centrais, já que a instalação destas não implica necessariamente em relações de concorrência ao centro. Por essa razão, sem negarmos o papel destas áreas centrais na redefinição da centralidade, ressaltamos a pertinência de qualifica-las na comparação entre os shopping centers, quanto à concentração espacial de franquias e filiais, a exclusividade da localização, o público alvo e abrangência de atuação.

Associado a essa necessária qualificação, destacamos o segundo ponto, que

\footnotetext{
${ }^{6}$ Essa importância é referente à concentração de estabelecimentos comerciais e de serviços, bem como à presença de franquias e filiais.
}

se refere a movimentos contrários à desconcentração espacial de franquias e filiais desde o centro principal, o que se dá a partir de nova concentração nesta área, resultante de lógicas espaciais que primam pelos segmentos socioeconômicos que a frequentam, de modo recorrente. Isso se soma à seletividade do processo de desconcentração espacial, posto que há ramos, organizados sobretudo em filiais, que exibem tal processo em menor intensidade e que apresentam preferência ao centro.

Podemos, então, afirmar que o centro principal constitui rugosidade (SANTOS, 1996), à medida que consiste em condição preexistente aos processos ligados ao policentrismo, do que é representativa a perda de importância que é apenas relativa ao que a área exibiu em períodos anteriores, combinada a dinâmicas de redefinição, com novos predomínios de camadas sociais atendidas e reajuste da composição de atividades, o que demonstramos pela inferência do público alvo das empresas e identificação das concentrações de franquias e filiais, atentando-nos para o peso dos ramos de atividades, como pode ser conferido nos quadros 1 a 9, a seguir discutidos.

Tendo em vista que as dinâmicas das diferentes áreas centrais estão fortemente articuladas, a compreensão da centralidade requer referência a um conjunto de escolhas por grupos empresariais, especialmente de capital externo, em suas lógicas espaciais. Estas levam em conta divisões territoriais do trabalho pretéritas materializadas em distintas áreas centrais que são redefinidas, por outro lado, por vetores externos, oriundos de ações de agentes hegemônicos.

\subsection{Análise comparativa da concentração e desconcentração espaciais de franquias e filiais \\ A comparação relacional ${ }^{7}$ entre as} atividades com maior número de franquias e

\footnotetext{
${ }^{7}$ Quando nos referimos a comparação relacional fazemos alusão à compreensão de área central, ou seus atributos, como atividades franqueadas e filiadas, que se dá pela relação da área a outros
} 
Ferreira, H. M.

\section{A CENTRALIDADE INTRAURBANA A PARTIR DA ANÁLISE DE FRANQUIAS E FILIAIS EM CIDADES MÉDIAS}

filiais na cidade de Presidente Prudente explicita distintas lógicas espaciais, associadas a diferentes escalas de atuação e processos socioespaciais de que são parte.

De antemão, frisamos que a análise se dá entre o centro principal e os shopping centers, já que as demais áreas centrais exibem complexidade menor do capital, ao menos para o caso das atividades que selecionamos. Também chamamos atenção para as escolhas locacionais mais específicas das franquias, que exibem lógicas que prezam por públicos segmentados, com preferência, portanto, por shopping centers e, em menor medida, eixos de desdobramento da área central no caso da cidade analisada.

Isso já havia sido apreendido por PortoSales (2014), segundo a qual a localização do empreendimento é fator fundamental, mensurado nos acordos contratuais de franqueamento, pois incide na lucratividade e no público atendido, numa expansão que se dá pela busca de parcela determinada de consumidores (PORTO-SALES, 2014). Ainda tratando da cidade em estudo, as filiais exibem, por sua vez, lógicas que primam pelo centro principal, atendendo ampla gama de segmentos socioeconômicos, ou, predominantemente, consumidores de camadas de baixo a médio poder aquisitivo.

Ressaltamos, com isso, os distintos processos de que são integrantes as lógicas espaciais de franquias e filiais, uma vez que, quanto às primeiras, verificamos que suas escolhas envolvem dinâmicas de segmentação dos espaços de consumo, ao passo que as segundas, ao exibirem preferências por maior gama de camadas sociais, reforçam centralidade da área central onde, de modo ímpar, isto é oferecido.

Para o caso do ramo de vestuário e calçados, os quadros 1 e 2 demonstram as tendências e as duas dinâmicas acima mencionadas.

\begin{tabular}{|c|c|c|c|}
\hline Filiais & Centro & Outras áreas centrais & Escalas de atuação \\
\hline Anticorpus & Não & Prudenshopping & Nacional \\
\hline \multirow[t]{2}{*}{ B1 } & \multirow[t]{2}{*}{ Sim } & P. S.Prudente** & \multirow[t]{2}{*}{ Regional } \\
\hline & & Prudenshopping & \\
\hline Barred's & Não & P. S.Prudente** & Nacional \\
\hline C\&A & Não & Prudenshopping & Nacional \\
\hline Centauro & Não & Prudenshopping & Nacional \\
\hline Chik's Center & Sim & Não & Regional \\
\hline Cia. do Terno & Não & Prudenshopping & Nacional \\
\hline Cowboys & Não & Subcentro Jardim Bongiovani & Regional \\
\hline Damyller & Sim & Não & Nacional \\
\hline Democrata & Não & Prudenshopping & Nacional \\
\hline Edubolsas & Sim & Não & Local \\
\hline Edubolsas Store & Não & Prudenshopping & Local \\
\hline Jô Calçados & Sim & Não & Nacional \\
\hline Magazine Tentação & Sim & Não & Regional \\
\hline Malhas Catarinense & Sim & Não & Regional \\
\hline Marisa & Não & Prudenshopping & Nacional \\
\hline Nelson Botti & Sim & Não & Local \\
\hline Patibum & Sim & Não & Regional \\
\hline Pé Quente & Sim & P. S.Prudente** & Local \\
\hline Pernambucanas & Sim & Não & Nacional \\
\hline Renner & Não & Prudenshopping & Nacional \\
\hline Riachuelo & Não & Prudenshopping & Nacional \\
\hline Spasso Calçados & Não & Avenida Washington Luiz & Nacional \\
\hline Tanger & Sim & Não & Regional \\
\hline Torra Torra & Sim & Não & Regional \\
\hline Vera Calçados & Sim & Subcentro $\mathrm{COHAB}$ & Local \\
\hline
\end{tabular}

espaços de consumo e ao conjunto da centralidade intraurbana. 
Ferreira, H. M.

\section{A CENTRALIDADE INTRAURBANA A PARTIR DA ANÁLISE DE FRANQUIAS E FILIAIS EM CIDADES MÉDIAS}

Quadro 1 - Presidente Prudente. Localização de filiais de comercialização de vestuário e calçados em áreas centrais e suas escalas de atuação, 2016. Fonte: Trabalhos de campo e sites de shopping centers e empresas descritas. ** Parque Shopping Prudente

\begin{tabular}{|c|c|c|c|c|}
\hline Franquias & Centro & Outras áreas centrais & $\begin{array}{c}\text { Investimento inicial } \\
(\mathrm{R} \$)\end{array}$ & Escalas de atuação \\
\hline Arena de Campeões & Não & Prudenshopping & $*$ & Nacional \\
\hline \multirow[t]{2}{*}{ Arezzo } & \multirow[t]{2}{*}{ Não } & Prudenshopping & \multirow[t]{2}{*}{375.000 a 635.000} & \multirow[t]{2}{*}{ Nacional } \\
\hline & & P. S.Prudente** & & \\
\hline Authentic Feet & Não & Prudenshopping & 400.000 a 643.500 & Nacional \\
\hline Brooksfield & Não & Prudenshopping & $*$ & Nacional \\
\hline \multirow[t]{2}{*}{ Bunny's } & \multirow[t]{2}{*}{ Não } & Prudenshopping & \multirow[t]{2}{*}{ Aprox. 20000} & \multirow[t]{2}{*}{ Nacional } \\
\hline & & P. S.Prudente** & & \\
\hline Carmen Steffens & Não & Prudenshopping & 370.000 a 720.000 & Internacional \\
\hline Colcci & Não & Prudenshopping & 499.500 & Nacional \\
\hline Container & Não & P. S.Prudente** & 100.000 a 300.000 & Nacional \\
\hline Ellus & Não & Prudenshopping & 400.000 a 450.000 & Nacional \\
\hline Equus & Não & Prudenshopping & $*$ & Nacional \\
\hline Forum & Não & Prudenshopping & 605.000 & Nacional \\
\hline Gregory & Não & Prudenshopping & Aprox. 200.000 & Nacional \\
\hline Havaianas & Sim & Prudenshopping & 75.000 a 845.000 & Nacional \\
\hline \multirow[t]{2}{*}{ Hering } & \multirow[t]{2}{*}{ Sim } & Prudenshopping & \multirow[t]{2}{*}{620.000 a 930.00} & \multirow[t]{2}{*}{ Nacional } \\
\hline & & P. S.Prudente** & & \\
\hline Hering Kids & Não & Prudenshopping & 620.000 a 930.00 & Nacional \\
\hline Hombre & Não & Prudenshopping & Aprox. 200.000 & Nacional \\
\hline Hope & Não & Prudenshopping & 125.000 a 375.000 & Nacional \\
\hline Jorge Bischoff & Não & Prudenshopping & 455.000 a 685.000 & Nacional \\
\hline \multirow{2}{*}{ Le Postiche } & \multirow[t]{2}{*}{ Não } & Prudenshopping & \multirow{2}{*}{ Aprox. 500.000} & \multirow{2}{*}{ Nacional } \\
\hline & & P. S.Prudente** & & \\
\hline Levi's & Não & Prudenshopping & Aprox. 550.000 & Internacional \\
\hline Lilica \& Tigor & Não & Prudenshopping & 370.000 a 490.000 & Nacional \\
\hline Líquido & Não & Prudenshopping & $*$ & Nacional \\
\hline Lupo & Não & Prudenshopping & 350.000 a 500.000 & Internacional \\
\hline M. Officer & Não & Prudenshopping & 460.000 a 550.000 & Nacional \\
\hline Magic Feet & Não & Prudenshopping & 280.000 a 476.875 & Regional \\
\hline Mr. Kitsch & Não & Prudenshopping & Aprox. 450.000 & Nacional \\
\hline My Shoes & Não & Prudenshopping & Aprox. 245.000 & Nacional \\
\hline \multirow[t]{2}{*}{ Piticas } & \multirow[t]{2}{*}{ Não } & Prudenshopping & \multirow[t]{2}{*}{150.000} & \multirow[t]{2}{*}{ Nacional } \\
\hline & & P. S.Prudente** & & \\
\hline Poderoso Timão & Não & Prudenshopping & 90.000 a 275.000 & Nacional \\
\hline Polo Play & Não & Prudenshopping & $*$ & Nacional \\
\hline Puc & Não & Prudenshopping & 458.000 a 566.000 & Nacional \\
\hline Restaura Jeans & Não & Prudenshopping & Aprox. 100.000 & Nacional \\
\hline Sandaliaria & Não & Prudenshopping & 120.000 a 250.000 & Nacional \\
\hline Sapataria do Futuro & Não & Prudenshopping & 149.000 a 300.000 & Nacional \\
\hline Side Walk & Não & Prudenshopping & 470.000 a 590.000 & Nacional \\
\hline Tennis One & Não & Prudenshopping & $*$ & Nacional \\
\hline Tip Top & Não & Prudenshopping & 422.000 & Nacional \\
\hline TNG & Não & Prudenshopping & $*$ & Nacional \\
\hline TVZ & Não & Prudenshopping & $*$ & Nacional \\
\hline \multirow[t]{2}{*}{ World Tennis } & \multirow[t]{2}{*}{ Não } & Prudenshopping & \multirow[t]{2}{*}{430.000 a 725.000} & Nacional \\
\hline & & P. S.Prudente** & & \\
\hline $\begin{array}{ll}\text { World } & \text { Tennis } \\
\text { Classic } & \\
\end{array}$ & Não & Prudenshopping & 430.000 a 725.000 & Nacional \\
\hline
\end{tabular}

Quadro 2 - Presidente Prudente. Localização de franquias de comercialização de vestuário e calçados em áreas centrais e suas escalas de atuação, 2016. Fonte: Trabalhos de campo e site de shopping centers, 
Ferreira, H. M.

\section{A CENTRALIDADE INTRAURBANA A PARTIR DA ANÁLISE DE FRANQUIAS E FILIAIS EM CIDADES MÉDIAS}

empresas descritas e ABF. * Os valores relativos ao investimento inicial não foram encontrados. ** Parque Shopping Prudente

No centro principal, as empresas do ramo de vestuário e calçados exibem redes regionais de lojas, em filiais que comercializam produtos a baixos preços e, não raramente, proporcionam cartões de crédito e empréstimos e configuram a tendência de grandes empresas em se interessarem pela expansão do consumo dos segmentos de baixa renda, como assinalou Silveira (2009).

Por seu turno, quanto às franquias localizadas no centro principal, verificamos que sua presença é substancialmente menor, com muitas delas também situadas em outros espaços de consumo, não exclusivas a esta área.

Entre as lojas franqueadas localizadas no principal shopping center, o Prudenshopping, estão marcas não situadas em outras áreas centrais. Nestes espaços, estão presentes franquias de preço elevado de aquisição e outras que exibem valores inferiores, mas que ofertam artigos de preços mais elevados, como é possível verificar na consulta aos produtos expostos. Enquanto na loja Hering artigos podem ser adquiridos a R\$ 10,00, em campanhas promocionais, em meio a produtos a $\mathrm{R} \$ 150,00$; na loja M. Officer, as peças são vendidas desde $\mathrm{R} \$ 150,00$, mas recorrentemente alcançam os $\mathrm{R} \$ 500,00$.

O Prudenshopping também conta com filiais de redes voltadas para a comercialização de artigos do vestuário e calçados aos segmentos de baixa e média renda, como Renner e C\&A. Ainda que possa sugerir se tratar de espaço popular de consumo, se o comparamos ao conjunto da cidade, é área central onde se concentram atividades voltadas a público com maior poder aquisitivo.

O Parque Shopping Prudente igualmente apresenta lojas voltadas aos públicos de médio a baixo poder de compra, como as Lojas Americanas e B1, em ainda maior concentração. Este shopping center conta com parcela considerável de estabelecimentos de capital externo, porém associada à maior expressividade daqueles de origem local e menor exclusividade.

No que se refere, portanto, ao ramo de comércio de vestuário e calçados, há expressiva expansão dos grandes grupos empresariais e opção por franqueamento, quando da busca em atender públicos restritos, localizadas, sobretudo, em shopping centers, contribuindo para o processo de segmentação socioespacial. Por outro lado, lojas de departamento exibem preferência pela expansão em filiais, situadas em shopping centers e no centro principal.

O ramo de serviços de alimentação apresenta tendência semelhante, com participação expressiva nas atividades que exibem processos de desconcentração espacial, sobretudo por franqueamento, situados principalmente nos shopping centers.

\begin{tabular}{|c|c|c|c|c|}
\hline Franquias & Centro & Outras áreas centrais & $\begin{array}{c}\text { Investimento inicial } \\
\text { (R\$) }\end{array}$ & Escalas de atuação \\
\hline Bob's & Não & Prudenshopping & $\begin{array}{l}269.000 \mathrm{a} \\
1.772 .000\end{array}$ & Internacional \\
\hline \multirow[t]{2}{*}{ Burger King } & \multirow[t]{2}{*}{ Não } & Prudenshopping & \multirow{2}{*}{$\begin{array}{c}1.000 .000 \mathrm{a} \\
3.500 .000\end{array}$} & \multirow[t]{2}{*}{ Internacional } \\
\hline & & Avenida Washington Luiz & & \\
\hline \multirow[t]{2}{*}{ Chiquinho Sorvetes } & \multirow[t]{2}{*}{ Sim } & Prudenshopping & \multirow[t]{2}{*}{190.000 a 405.000} & \multirow[t]{2}{*}{ Nacional } \\
\hline & & P. S.Prudente** & & \\
\hline Fábrica di Chocolate & Não & Prudenshopping & 71.900 a 114.400 & Nacional \\
\hline Flavored Popcorn & Não & Prudenshopping & 76.000 a 93.500 & Nacional \\
\hline Fran's Café & Não & Prudenshopping & 434.000 a 464.200 & Nacional \\
\hline Gelatos Parmalat & Não & Prudenshopping & A partir de 225.000 & Nacional \\
\hline Giraffas & Não & Prudenshopping & $\begin{array}{l}170.000 \mathrm{a} \\
1.360 .000\end{array}$ & Nacional \\
\hline Gygabon & Sim & Não & $*$ & Regional \\
\hline
\end{tabular}


Ferreira, H. M.

\section{A CENTRALIDADE INTRAURBANA A PARTIR DA ANÁLISE DE FRANQUIAS E FILIAIS EM CIDADES MÉDIAS}

\begin{tabular}{|c|c|c|c|c|}
\hline Habib's & Não & Prudenshopping & $\begin{array}{c}900.000 \mathrm{a} \\
2.5000 .000\end{array}$ & Nacional \\
\hline \multirow[t]{2}{*}{ Ice by Nice } & \multirow[t]{2}{*}{ Não } & Avenida Washington Luiz & \multirow[t]{2}{*}{$*$} & \multirow[t]{2}{*}{ Regional } \\
\hline & & Prudenshopping & & \\
\hline Ice Creamy Sorvetes & Não & Prudenshopping & 70.000 a 330.000 & Nacional \\
\hline Jin Jin Sushi & Não & Prudenshopping & * & Nacional \\
\hline Massashin & Não & Prudenshopping & * & Internacional \\
\hline \multirow[t]{2}{*}{ Mc Donald's } & \multirow[t]{2}{*}{ Não } & Prudenshopping & \multirow{2}{*}{$\begin{array}{c}1.675 .000 \mathrm{a} \\
2.680 .000\end{array}$} & \multirow[t]{2}{*}{ Internacional } \\
\hline & & Avenida Washington Luiz & & \\
\hline Mr. Beer & Não & Prudenshopping & 74.000 a 261.500 & Nacional \\
\hline Nutty Bavarian & Não & Prudenshopping & 70.000 a 109.000 & Internacional \\
\hline Old Dog Dogueria & Sim & Parque do Povo & $*$ & Regional \\
\hline Pastel do Alemão & Sim & Parque do Povo & $*$ & Regional \\
\hline \multirow[t]{2}{*}{ Roasted Potato } & \multirow[t]{2}{*}{ Não } & Prudenshopping & \multirow[t]{2}{*}{265.000 a 440.000} & \multirow[t]{2}{*}{ Nacional } \\
\hline & & P. S.Prudente** & & \\
\hline Scada Café & Sim & Prudenshopping & 90.000 a 350.000 & Nacional \\
\hline Sodiê Doces & Sim & Não & 260.000 a 460.000 & Nacional \\
\hline \multirow[t]{2}{*}{ Subway } & \multirow[t]{2}{*}{ Não } & Prudenshopping & \multirow[t]{2}{*}{300.000 a 580.000} & \multirow[t]{2}{*}{ Internacional } \\
\hline & & $\begin{array}{c}\text { Subcentro Jardim } \\
\text { Bongiovani }\end{array}$ & & \\
\hline \multirow[t]{2}{*}{ Suco Bagaço } & \multirow[t]{2}{*}{ Não } & Prudenshopping & \multirow[t]{2}{*}{185.000 a 295.000} & \multirow[t]{2}{*}{ Nacional } \\
\hline & & P. S.Prudente** & & \\
\hline Tempero Manero & Sim & Não & $*$ & Nacional \\
\hline Top Churro & Não & Prudenshopping & Aprox. 80.000 & Nacional \\
\hline
\end{tabular}

Quadro 3 - Presidente Prudente. Localização de franquias de serviços de alimentação em áreas centrais e suas escalas de atuação, 2016. Fonte: Trabalhos de campo e site de shopping centers, empresas descritas e ABF. * Os valores relativos ao investimento inicial não foram encontrados. ** Parque Shopping Prudente.

\begin{tabular}{|l|l|l|l|}
\hline \multicolumn{1}{|c|}{ Filiais } & \multicolumn{1}{c|}{ Centro } & \multicolumn{1}{c|}{ Outras áreas centrais } & \multicolumn{1}{c|}{ Escalas de atuação } \\
\hline Pizzaria Donna Oliva & Sim & Parque do Povo & Regional \\
\hline SiqGrill & Não & Prudenshopping & Local \\
\hline
\end{tabular}

Quadro 4 - Presidente Prudente. Localização de filiais de serviços de alimentação em áreas centrais e suas escalas de atuação, 2016. Fonte: Trabalhos de campo e site de shopping centers e empresas descritas.

São estabelecimentos franqueados de empresas de escalas nacional e internacional de atuação, que exibem preços diferenciados de aquisição das franquias. Os valores mais baixos giram em torno de $\mathrm{R} \$ 70.000,00$, como a Fábrica Di Chocolate, de capital nacional, ao passo que os mais elevados alcançam $\mathrm{R} \$ 3.500 .000,00$, a exemplo do Burger King, de escala internacional.

As lógicas espaciais de franquias de fast-food também primam por eixos de desdobramento, de expressivo fluxo de veículos. Neste caso, estão situados em amplos imóveis, maiores que aqueles localizados em shopping centers, além de contarem com estacionamentos exclusivos à empresa, o que permite, por conseguinte, acessibilidade e prestação de serviços de drive-thru. São ilustrativos os restaurantes Burger King e McDonald's.

No centro principal, há uma expressiva concentração espacial de estabelecimentos deste ramo, que, todavia, não estão, de modo predominante, organizados em redes de franquias ou filiais, com participação majoritária de empresas de capitais locais. São exceção alguns casos de sorveterias, cafés e restaurantes de capital regional, principalmente.

Em síntese, este ramo apresenta lógicas espaciais de franquias que primam por espaços segmentados, a exemplo de shopping centers e, em menor medida, eixos de desdobramento da área central, atentos às demandas sociais mais recentes, como rapidez na aquisição de serviços e necessidade de áreas de estacionamento. Por outro lado, o centro 
Ferreira, H. M.

\section{A CENTRALIDADE INTRAURBANA A PARTIR DA ANÁLISE DE FRANQUIAS E FILIAIS EM CIDADES MÉDIAS}

principal é pouco preferencial a estes capitais, o que coincide com a precária presença destes dois fatores.

Em movimentos contrários às lógicas de empresas de comercialização de vestuários e calçados e de prestação de serviços alimentícios, há ramos de atividades que compõem processo de concentração espacial no centro principal, por meio de estabelecimentos vinculados a empresas de escalas de atuação regional, nacional e, em menor número, internacional. Isto se dá com a permanência de divisões de trabalho pretéritas e a instauração de novas lógicas, em que empresas consideram o centro como área primordial para localização dos estabelecimentos.

O ramo de eletroeletrônicos apresenta contínua concentração espacial no centro principal, combinada à instalação de estabelecimentos em outros espaços, numa tendência secundária, todavia. No centro principal, as empresas estão presentes por meio de filiais, submetidas a vínculos e interações espaciais com capitais de diferentes escalas de atuação, mas especialmente nacional.

\begin{tabular}{|c|c|c|c|}
\hline Filiais & Centro & Outras áreas centrais & Escalas de atuação \\
\hline BJ Santos & Sim & Não & Regional \\
\hline Casas Bahia & Sim & Prudenshopping & Nacional \\
\hline Cybelar & Sim & Não & Regional \\
\hline J. Mahfuz & Sim & Não & Regional \\
\hline Lojas Americanas & Não & P. S.Prudente** & Nacional \\
\hline Magazine Luiza & Sim & Prudenshopping & Nacional \\
\hline Pernambucanas & Sim & Não & Nacional \\
\hline Polishop & Não & Prudenshopping & Nacional \\
\hline Ponto Frio & Sim & Não & Nacional \\
\hline
\end{tabular}

Quadro 5 - Presidente Prudente. Localização de filiais de comércio de eletroeletrônicos em áreas centrais e suas escalas de atuação, 2016. Fonte: Trabalhos de campo e site de shopping centers e empresas descritas. ** Parque Shopping Prudente.

\begin{tabular}{|c|c|c|c|c|}
\hline Franquias & Centro & Outras áreas centrais & Investimento inicial (R\$) & Escalas de atuação \\
\hline Multicoisas & Não & Prudenshopping & 642.000 a 744.000 & Nacional \\
\hline My Store & Não & Prudenshopping & $*$ & Internacional \\
\hline Samsung & Não & Prudenshopping & $*$ & Internacional \\
\hline
\end{tabular}

Quadro 6 - Presidente Prudente. Localização de franquias de comércio de eletroeletrônicos em áreas centrais e suas escalas de atuação, 2016. Fonte: Trabalhos de campo e site de shopping centers, empresas descritas e ABF. * Os valores relativos ao investimento inicial não foram encontrados.

No quadro 6, relativo à localização de franquias de comércio de eletroeletrônicos, podemos observar que, de modo díspar às lógicas que primam pelo centro principal, estas privilegiam outros espaços, especialmente shopping centers, associados ao capital internacional e ao franqueamento.

O ramo de eletroeletrônicos apresenta, com isso, duas tendências contrárias, uma relacionada ao reforço da centralidade do centro principal e outra, à importância das novas áreas centrais. Todavia, como podemos conferir nos quadros 5 e 6 , a intensidade da primeira tendência se sobressai.

Outro ramo que exemplifica as dinâmicas de concentração e desconcentração espaciais de atividades são o dos bancos. Há concentração de atividades no centro principal, onde estão presentes de modo expressivo, ainda que nas últimas décadas, conforme Oliveira (2014), tenham exibido desconcentração de agências.

\begin{tabular}{|l|l|l|l|}
\hline Filiais & Centro & Outras áreas centrais & $\begin{array}{l}\text { Escalas de } \\
\text { atuação }\end{array}$ \\
\hline Banco do Brasil & $\operatorname{Sim}(2)$ & P. S.Prudente & Internacional \\
\hline
\end{tabular}


Ferreira, H. M.

A CENTRALIDADE INTRAURBANA A PARTIR DA ANÁLISE DE FRANQUIAS E FILIAIS EM CIDADES MÉDIAS

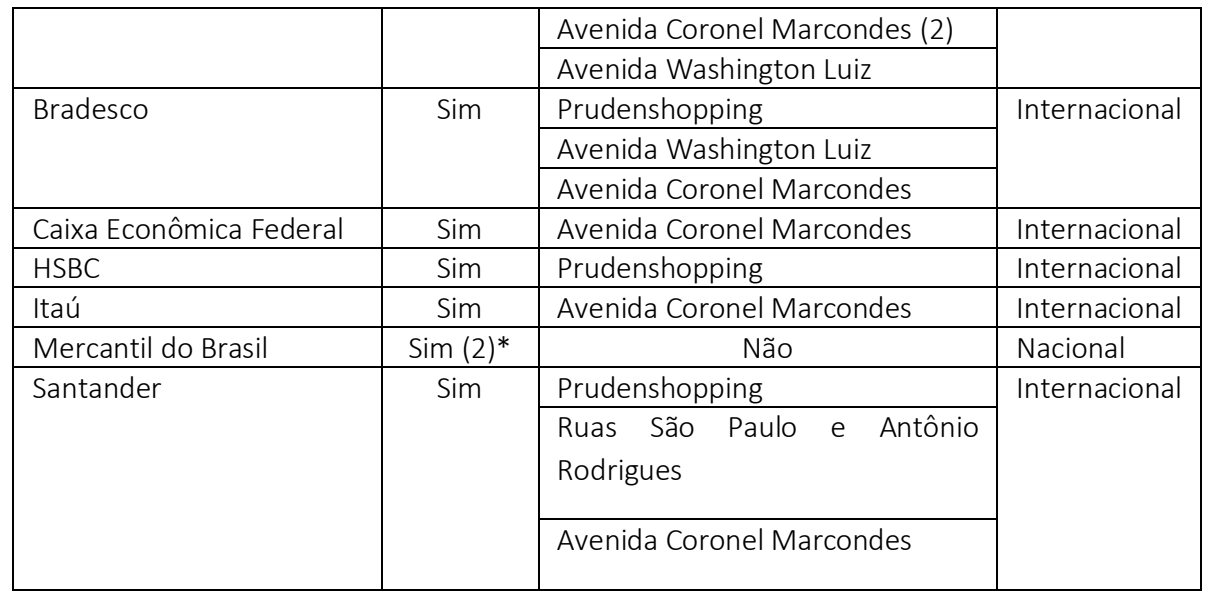

Quadro 7 - Presidente Prudente. Localização de filiais de bancos em áreas centrais e suas escalas de atuação, 2016. Fonte: Trabalhos de campo e site de shopping centers e empresas descritas. * Entre parênteses estão os números de unidades quando estas se encontram acima de um estabelecimento.

As dinâmicas deste ramo que, apesar de movimentos de desconcentração espaciais, estão predominantemente situados no centro principal, influenciam as lógicas espaciais de financeiras, que exibem lógicas espaciais, as quais buscam atender o público alvo dos bancos.

\begin{tabular}{|c|c|c|c|}
\hline Filiais & Centro & Outras áreas centrais & Escalas de atuação \\
\hline BV Financeira & Sim & Não & Nacional \\
\hline Crefisa & Sim & Não & Nacional \\
\hline Daycred & Sim & Não & Nacional \\
\hline Losango & Sim & Não & Nacional \\
\hline Omni Créditos e Financiamentos & Sim & Não & Nacional \\
\hline Siccobcred & Sim & Não & Regional \\
\hline
\end{tabular}

Quadro 8 - Presidente Prudente. Localização de filiais de financeiras em áreas centrais e suas escalas de atuação, 2016. Fonte: Trabalhos de campo e site de shopping centers e empresas descritas.

\begin{tabular}{|c|c|c|c|c|}
\hline Franquias & Centro & Outras áreas centrais & Valor de aquisição & Escalas de atuação \\
\hline Health Cred & $\operatorname{Sim}$ & Não & $*$ & Nacional \\
\hline
\end{tabular}

Quadro 9 - Presidente Prudente. Localização de franquias de financeiras em áreas centrais e suas escalas de atuação, 2016. Fonte: Trabalhos de campo e site de shopping centers e empresas descritas. ${ }^{*}$ Os valores relativos ao investimento inicial não foram encontrados.

Como reforço da centralidade do centro principal, as financeiras apresentam lógicas que privilegiam esta área, situadas, sobretudo, nas proximidades de agências bancárias, no propósito de atender clientelas não enquadradas nas exigências burocráticas das instituições para a concessão de empréstimos, exercendo, por isso, papel fundamental na expansão do consumo, por meio, de filiais que estabelecem interações com sedes de empresas de escala nacional de atuação.
Com efeito, apesar de lógicas que buscam proximidade com agências bancárias que apresentam, todavia, tendências concomitantes de concentração e desconcentração espaciais, as financeiras não exibem esta última dinâmica, um representativo da forte permanência de agências bancárias no centro principal.

Para efeito de síntese, expomos no quadro 10 as dinâmicas dos distintos ramos de atividades, que apresentam movimentos contrários, considerando lógicas espaciais escalas de atuação predominantes. 
Ferreira, H. M.

\section{A CENTRALIDADE INTRAURBANA A PARTIR DA ANÁLISE DE FRANQUIAS E FILIAIS EM CIDADES MÉDIAS}

\begin{tabular}{|c|c|c|}
\hline VC & $\begin{array}{l}\text { Concentração espacial absoluta semelhante } \\
\text { entre o centro e shopping centers, embora em } \\
\text { maior densidade nos últimos. }\end{array}$ & $\begin{array}{l}\text { As empresas localizadas no centro apresentam, } \\
\text { principalmente, atuação regional, ao passo que aquelas } \\
\text { situadas em shopping centers, escalas nacional e } \\
\text { internacionail. }\end{array}$ \\
\hline$A$ & $\begin{array}{l}\text { Preferência expressiva pela localização em } \\
\text { shopping centers. }\end{array}$ & tuação sobretudo nacional e \\
\hline$E$ & $\begin{array}{l}\text { Maior concentração espacial absoluta e relativa } \\
\text { no centro, paralela à oferta em menor medida e } \\
\text { diversidade em hipermercados e shopping } \\
\text { centers }\end{array}$ & $\begin{array}{l}\text { No centro, as empresas exibem atuação regional e nacional, } \\
\text { enquanto nos shopping centers, nacional e internacional }\end{array}$ \\
\hline B & $\begin{array}{l}\text { Número mais significativo no centro, } \\
\text { concomitantemente ao processo de } \\
\text { desconcentração espacial }\end{array}$ & $\begin{array}{l}\text { Em todas as áreas centrais em que se encontram, as escalas } \\
\text { de atuação são nacional e internacional. }\end{array}$ \\
\hline$F$ & $\begin{array}{l}\text { Localizadas quase exclusivamente no centro, } \\
\text { próximas a bancos. }\end{array}$ & Escalas de atuação regional e nacional. \\
\hline
\end{tabular}

Quadro 10 - Síntese dos processos, lógicas e escalas, conforme os ramos de atividades. Legenda - VC: Vestuário e calçados; A: Alimentação; E: Eletroeletrônicos; B: Bancos e F: Financeiras. Org.: A autora.

Se há ramos, portanto, que em sua dinâmica espacial denotam perda de importância do centro principal, identificamos, por outro lado, que este processo é dialético, com permanência de ramos nesta área e novas concentrações. A despeito, portanto, do policentrismo, com a emergência de novas áreas centrais, o centro principal constitui condição preexistente a este processo, uma vez que lógicas espaciais de diferentes ramos indicam escolhas por esta área, em reforço de sua centralidade.

\section{CONCLUSÕES}

Em análise comparativa e relacional, buscamos compreender as áreas centrais de cidades médias policêntricas por meio da complexidade do capital das empresas, identificada principalmente pela presença de franquias e filiais. A partir disso, destacamos alguns pontos.

$\mathrm{O}$ primeiro deles se refere às distintas lógicas espaciais conforme as atividades desenvolvidas e modos de organização, representativos de dessemelhantes processos espaciais. As lógicas concernentes aos ramos de comércio de vestuário e calçados e serviços de alimentação exibem preferência por novos espaços de consumo, a partir, principalmente de franquias, em densas interações com outros centros da rede urbana. Estes dois casos são parte dos processos de desconcentração de atividades e segmentação dos espaços de consumo, visto que tais lógicas buscam públicos específicos e exclusivos.

Por outro lado, lógicas que intentam atender maior variedade de segmentos socioeconômicos, ou de modo mais intenso as camadas de média e baixa renda, primam pela localização no Centro, pela diversidade de níveis de renda presentes, a despeito da tendência expressiva à "popularização". Se, como no caso do comércio de vestuário e calçados, são empresas com menor abrangência de atuação, na prestação de serviços bancários, por exemplo, a densidade de interações espaciais é expressiva.

Uma vez que o centro principal permanece como importante espaço de consumo e as repercussões das novas áreas centrais merecem relativização, concordamos com Santos (1994), portanto, quando afirma que os eventos e processos não implicam em estruturas novas, uma vez que estão sujeitos e amalgamados ao que preexiste, que sofre, dialeticamente, redefinições.

\section{REFERÊNCIAS}

BRENNER, N. Restructuring, Rescaling, and the Urban Question. Critical Planning. Summer 2009.

CATELAN, M. J. As interações espaciais interescalares: o potencial de consumo das 


\section{A CENTRALIDADE INTRAURBANA A PARTIR DA ANÁLISE DE FRANQUIAS E FILIAIS EM CIDADES MÉDIAS}

cidades médias na rede urbana. In: Seminário Internacional RII e VI Taller de editores Rier, XIII, 2014, Salvador, p. 1-15.

CASTRO, A. F. V.; ENGEL, P. E. Reestruturação e shopping centers, aspectos concernentes ao rearranjo da centralidade em cidades de porte médio. Revista Formação, n. 22, v. 2, p. 28-48, 2015.

CLEPS, M. D. G. O comércio e a cidade: novas territorialidades urbanas. Sociedade \& Natureza, v. 16, n. 30, p. 117-132, 2004.

CORRÊA, R. L. Globalização e reestruturação da rede urbana - uma nota sobre as pequenas cidades. Revista Território, v. 4, n, 6, 1999.

HARVEY, D. Condição pós-moderna. Trad. Adail Ubirajara Sobral e Maria Stela Gonçalves. São Paulo: Edições Loyola, 1992.

LENCIONI, S. Concentração e centralização das atividades urbanas: uma perspectiva multiescalar. Reflexões a partir do caso de São Paulo. Revista de Geografia Norte Grande, 39, 2008. p. 7-20.

LOZANO, L. P. G; SPOSITO, E. S. Cidades médias e distribuição espacial do comércio de eletrodomésticos no Brasil. In: Carmen Bellet, Maria Encarnação Beltrão Sposito, Everaldo Santos Melazzo, José Maria Llop. (Org.). Urbanización, producción y consumo en ciudades medias/intermedias. 1ed.Lleida: Edicions de la Universitat de Lleida, 2015, v. 1, p. 79-106.

MATTOS, A. B. Lógicas espaciais das empresas franqueadas do ramo comercial de confecções e calçados: cidades médias e consumo. Caminhos de Geografia, v. 17, n, 57, p. 175-190, 2016.

MELAZZO, E. S; CASTRO, C. A. A escala geográfica: noção, conceito ou teoria? Terra Livre, v. 2, p. 133-142, 2008.

OLIVEIRA JÚNIOR, G. A. Redefinição da centralidade urbana em cidades médias. Sociedade \& Natureza, Uberlândia, p. 205-220, 2008.

OLIVEIRA, J. S. As lógicas espaciais do sistema bancário: reestruturação na cidade de
Presidente Prudente-SP. In: Seminário Nacional de Integração da Graduação e Pós-graduação em geografia, Semana de geografia, Encontro de estudantes de licenciatura em Geografia, I, 2014, Presidente Prudente.

ORTIGOZA, S. A. G. As franquias e as novas estratégias do comércio urbano no Brasil. 1996. Dissertação (Mestrado em Geografia) - Instituto de Geociências e Ciências Exatas, Universidade Estadual Paulista, Rio Claro.

RAMOS, C. S. A geografia do comércio eletrônico (e-commerce) no Brasil: o exemplo do varejo. Geografia, Rio Claro, v. 28, n. 1, p. 63-81, 2003.

PEREIRA, S. R. Expansão e estruturação do espaço urbano de Presidente Prudente-SP. Formação, Presidente Prudente, v.1, p. 31-67, 2002.

PORTO-SALES, A. L. A situação espacial de franquias na América do Sul: morfologia e centralidade urbana em cidades médias na Argentina, Brasil e Chile. 2014. 281 f. Tese (Doutorado em Geografia) - Faculdade de Ciências e Tecnologia, Universidade Estadual Paulista, Presidente Prudente.

PINTAUDI, S. M. O Shopping Center no Brasil. Condições de Surgimento e Estratégias de Localização. In: PINTAUDI, S. M; FRÚGOLI JÚNIOR, H. Shopping Centers. Espaço, cultura e modernidade nas cidades brasileiras. São Paulo: Editora Unesp, 1992, p. 15-44.

SALGUEIRO, T. B. Do comércio à distribuição: o roteiro de uma mudança. Oeiras: Celta, 1996.

SANTOS, M. A natureza do espaço: técnica e tempo, razão e emoção. São Paulo: Hucitec, 1996.

Metamorfoses do espaço habitado. Fundamentos teóricos e metodológicos da Geografia. São Paulo: Hucitec, 1994.

SILVA, V. L. S. Formas plurais no Franchising de Alimentos: Evidências de Estudos de Caso na França e no Brasil. RAC, 1a Edição Especial, 2007. p. 129-152. 


\section{A CENTRALIDADE INTRAURBANA A PARTIR DA ANÁLISE DE FRANQUIAS E FILIAIS EM CIDADES MÉDIAS}

SILVEIRA, M. L. A natureza relacional da teoria dos circuitos da economia urbana. In:

Geografia urbana: Ciência e ação política. Rio de Janeiro: Consequência, 2014, p. 155-178.

Finanças, Consumo e Circuitos da Economia Urbana na Cidade de São Paulo. Caderno CRH, v. 22, n. 55, p. 65-76, 2009.

Escala geográfica: da ação ao império? Terra Livre, v. 2, n. 23, 2004.

SODRÉ, R.; PEREIRA, A. J. Rede urbana e relações interescalares na cidade média de Araguaína: perspectivas a partir do comércio de vestuário. Geotextos, v. 11, n. 2, 2015.

SOJA, E. W. Geografias pós-modernas. A reafirmação do espaço na teoria social crítica. Rio de Janeiro: Jorge Zahar, 1993.

SPOSITO, M. E. B. O centro e as formas de expressão da centralidade urbana. REVISTA DE GEOGRAFIA. São Paulo: UNESP, n.10, p. 1-18, 1991.

Cidades médias: reestruturação da cidade e reestruturação urbana. In: SPOSITO, M. E. B. (org.). Cidades médias: espaços em transição. São Paulo: Expressão Popular, 2007a. p. 233-253.

Novas formas comerciais e redefinição da centralidade intra-urbana In: (org.) Textos e contextos para a leitura geográfica de uma cidade média. Presidente Prudente: Pósgraduação em Geografia da FCT/UNESP, 2001. p. 235-254.

O desafio metodológico da abordagem interescalar no estudo de cidades médias no mundo contemporâneo. Cidades, v. 3, n. 5, p. 143-157, 2006.

- Segregação socioespacial e centralidade urbana. In: VASCONCELOS, P. A.; CORRÊA, R. L.; PINTAUDI, S. M.; A cidade contemporânea. Segregação espacial. São Paulo: Contexto, 2013. p. 61-94.

Reestruturação urbana e segregação socioespacial no interior paulista. Scripta Nova, v. XI, p. 11, 2007.
VILLAÇA, F. Espaço intra-urbano no Brasil. São Paulo: Studio Nobel, 2001.

WHITACKER, A. M. A produção do espaço urbano em Presidente Prudente: uma discussão sobre a centralidade urbana. 1997. Dissertação (Mestrado em Geografia) - Faculdades de Ciência e Tecnologia, Universidade Estadual Paulista, Presidente Prudente.

Centro consolidado e centro principal. 2015. [No prelo] Inovações tecnológicas, mudanças nos padrões locacionais e na configuração da centralidade em cidades médias. Scripta Nova. Revista Electrónica de Geografía y Ciencias Sociales, v. 11, n. 245, 2007.

Reestruturação urbana e centralidade em São José do Rio Preto. 2003 (Doutorado em Geografia) - Faculdade de Ciência e Tecnologia, Universidade Estadual Paulista, Presidente Prudente. 